\title{
EVOLUCIÓN DE LA PLAYA DE SA RIERA (Cap de Begur, Costa Brava) EN LOS ÚLTIMOS 50 AÑOS
}

\author{
Anna Crous Bou y Josep Pintó Fusalba \\ Departament de Geografia, Història i Història de l'Art \\ Universitat de Girona
}

\section{RESUMEN}

En las últimas décadas la regulación de los caudales fluviales mediante la construcción de presas y esclusas junto con la modificación antrópica de la línea de costa ha provocado una alteración de la dinámica litoral que se ha manifestado principalmente en los tramos de costa baja. Antiguas costas de acumulación han pasado a ser actualmente zonas bajo el predominio de los procesos erosivos o en el mejor de los casos a mantener el equilibrio en el balance sedimentario.

En este marco general de penuria sedimentaria de las costas bajas la playa de Sa Riera se distingue por estar sujeta a una dinámica litoral de signo opuesto ya que en las últimas cinco décadas ha experimentado una acreción generalizada.

Mediante la utilización de fotografías aéreas y su tratamiento en un sistema de información geográfica (SIG), se han podido establecer la tasa y el ritmo de progradación de la playa, estimándose en 46 metros el avance máximo sufrido por la línea de costa en estos cincuenta años.

También se ha podido comprobar como dicha acreción es percibida por un determinado perfil de usuario de playa como un impacto desfavorable para sus actividades en el litoral.

Palabras clave: progradación, cambio costero, SIG, Sa Riera, Costa Brava.

* El trabajo descrito en este artículo se ha realizado en el marco de los proyectos BSO22002-04-04250C02-02: «Cartografía y modelización de la evolución del paisaje litoral de Cataluña: 1800-2000», y REN200309029-C03-02/ Subprograma MAR: «Desarrollo y validación de un método de valoración del recurso playa como ayuda a la gestión integrada de zonas turísticas costeras», que han recibido una ayuda del Programa Nacional de proyectos de I+D del Ministerio de Ciencia y Tecnología. Este artículo fue presentado como comunicación en el XVIII Congreso del AGE celebrado en Bellaterra (Barcelona) en septiembre de 2003. 


\section{ABSTRACT}

Accretion processes are characteristics of coastal sand plains and they produce the development of beaches and others coastal accumulation forms. However, the natural evolution in a lot of coastal areas has changed in the last decades and they have been converted in shorelines where erosion processes take place.

Sa Riera beach is singular in the context described above because it has advanced by more than $45 \mathrm{~m}$ during the last decades. Aerial photographs have been used to establish accretion rates since 1956 until 2003.

Furthermore, it has been observed how accretion was taken as a negative impact by a concrete set of beach users.

Key words: accretion, coastal dynamics, coastal change, Sa Riera.

\section{Introducción}

En el marco de un proyecto sobre la cartografía de la evolución del paisaje litoral de Cataluña en los últimos dos siglos se ha planteado una línea de investigación centrada en el análisis del cambio costero en un conjunto de playas seleccionadas del litoral catalán. El objetivo de dicha línea de trabajo es establecer las tasas de erosión o acreción sufridas durante los últimos 50 años, analizar los factores condicionantes y evaluar las consecuencias socioeconómicas de los cambios.

Una de las playas seleccionadas para llevar a cabo dicho estudio ha sido la cala de Sa Riera, situada en la unidad de paisaje litoral «Montañas de Begur», en el sector central de la Costa Brava (Girona). Dicha playa fue seleccionada por presentar en los últimos años un balance sedimentario positivo que ha provocado una notable acreción de la superficie de playa.

En los análisis multitemporales del cambio costero es frecuente utilizar como fuente de datos las imágenes proporcionadas por los sensores remotos. En esta investigación se usaron fotografías aéreas a escalas que variaban entre 1:12.000 y 1:33.000 según el año del vuelo.

Un aspecto básico cuando se utiliza este tipo de fuente es el establecimiento de la línea de orilla. En este caso se adoptó como tal el límite entre la playa húmeda y la playa seca. Como indican Morales y Tejada (1997) es de fácil reconocimiento en la fotografía aérea y tiene poca movilidad en el ciclo de marea: entre 1 y 2 metros, valores que aún son más reducidos en el caso del litoral mediterráneo. El error estimado en el uso de este tipo de fuente depende también de la escala y en el caso de las costas mediterráneas trabajos anteriores lo han evaluado entre 0,88 y 3,5 m (Bou, 1994; Ortiz, 1997).

\section{Objetivos}

La principal finalidad para la que se realizan muchos de los estudios en torno a la evolución de las zonas costeras es la de obtener una visón general del estado de la cuestión para posteriormente predecir y determinar futuras actuaciones en el marco de una buena planificación del espacio litoral.

Por todo ello el objetivo prioritario del presente estudio es el de analizar y cuantificar la evolución de un sector costero, poniendo en práctica todo un conjunto de herramientas, cálculos y métodos ya aplicados en otros tramos de costa, además de determinar las consecuencias que tanto en el ámbito natural como social se producen cuando se producen cambios ambientales. 


\section{Situación de la Cala de Sa Riera}

La playa de la Sa Riera se localiza en el sector central de la Costa Brava. Es una pequeña bahía abrigada situada en la vertiente norte del cabo de Begur, abierta al noreste y donde desemboca un pequeño torrente. Administrativamente pertenece al municipio de Begur.

La cala tiene una longitud de 200 metros y una anchura que varia entre los 40 y los $80 \mathrm{~m}$ y se encuentra limitada en sus extremos por acantilados de altura moderada, que se extienden en dirección norte hasta la playa de Illa Roja. y en dirección sur hasta la Punta de la Creu.

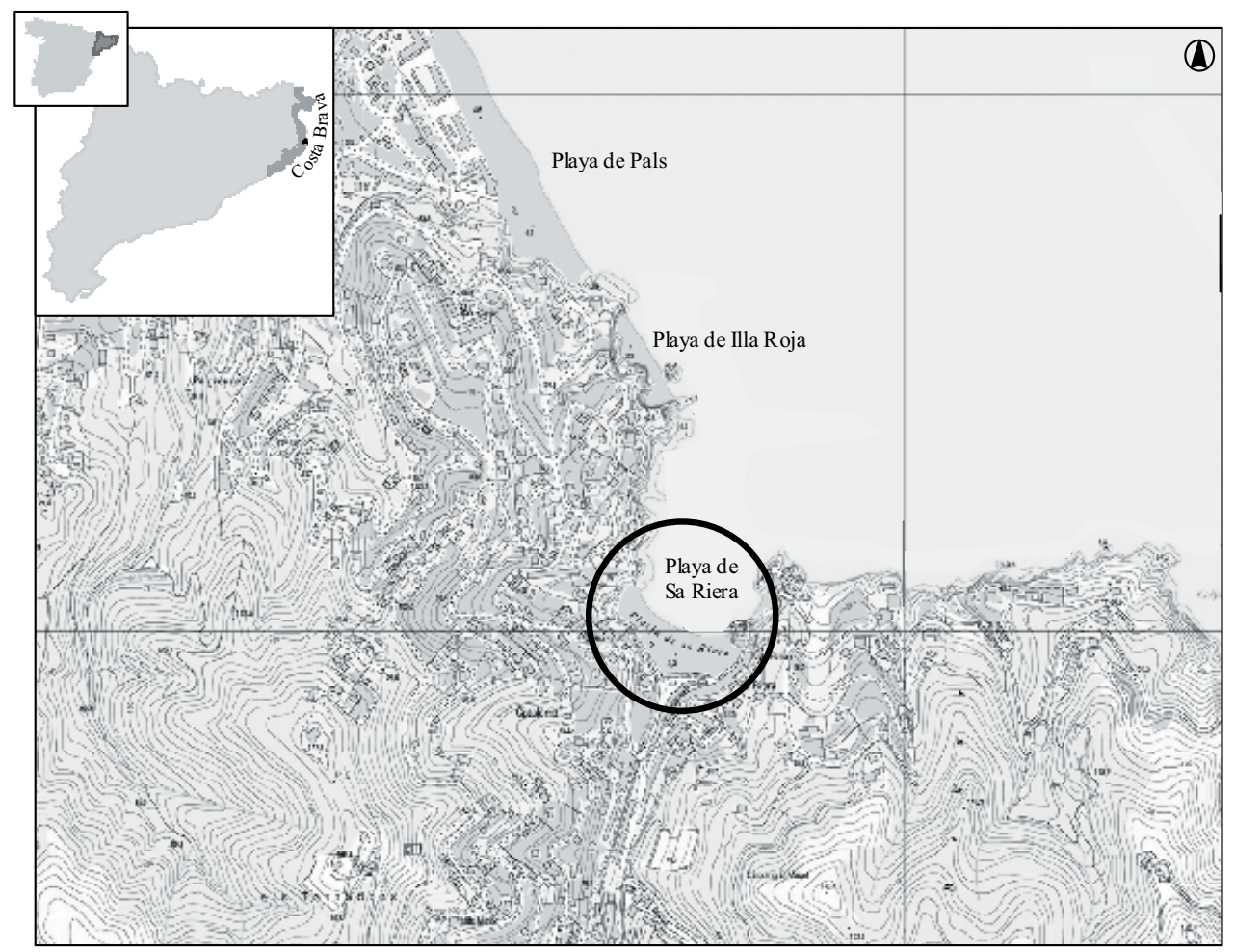

Figura 1. Situación de la playa de Sa Riera en la Costa Brava (Girona).

Los vientos dominantes, sin tener en cuenta las brisas, son los procedentes del suroeste y los de componente norte. Los de norte y noreste son los que soplan con más intensidad, lo que explica la coincidencia de la procedencia de las direcciones de oleaje más frecuentes.

\section{El cambio costero en Sa Riera}

\subsection{Metodología}

El estudio de la evolución de la línea de costa se ha abordado mediante el análisis de fotografías aéreas. Los Sistemas de Información Geográfica (SIG) permiten la obtención y 
el almacenamiento de los datos obtenidos y posteriormente su tratamiento para cuantificar y plasmar cartográficamente los cambios en la superficie de la playa.

El principal dato que se requiere para la cuantificación de la evolución de la playa, es la línea de costa. Las líneas costeras de distintos años nos permiten observar la diferencia entre ellas, establecer comparaciones, determinar los cambios y calcular la tasa de evolución (expresada en metros de avance o retroceso al año), útil para una posterior proyección futura y para una correcta gestión y planificación del territorio litoral.

\subsubsection{Materiales}

\section{A) Fotografía aérea}

Las fotografías aéreas constituyen el documento básico para la obtención de información sobre la morfología costera. Se utilizaron para obtener la línea de costa de los años 1957, 1964, 1977 i 1991. La escala i procedencia de los distintos vuelos utilizados en este trabajo están resumidas en el cuadro 1:

Cuadro 1

CARACTERÍSTICAS DE LAS FOTOGRAFÍAS AÉREAS UTILIZADAS

\begin{tabular}{|c|c|c|}
\hline Año & Escala & Vuelo \\
\hline 1957 & $1: 30.000$ & americano \\
\hline 1964 & $1: 12.000$ & ICC \\
\hline 1977 & $1: 30.000$ & IGN \\
\hline 1991 & $1: 22.000$ & ICC \\
\hline
\end{tabular}

\section{B) Cartografía digital}

La línea de costa de los años posteriores a 1991 se obtuvo de los ortofotomapas en blanco y negro, a escala 1:5000, editados por el Institut Cartogràfic de Calalunya (ICC) y correspondientes al vuelo de 1998.

\section{C) Sistemas de Posicionamiento Global (GPS)}

Durante el año 2003 se efectuó una campaña de trabajo de campo para obtener la posición actual de la línea de costa. Se utilizó un GPS equipado con un sistema de captación de señal rasante para mejorar la precisión de las medidas que se obtienen con el equipo estándar. El usos de los GPS se ha revelado como una de las técnicas más eficientes en las medidas de los cambios costeros (Ortiz, 2001).

\section{D) Fotografias antiguas}

La comparación entre imágenes antiguas y actuales de una misma zona permite constatar los cambios, a veces espectaculares, que se producen en el paisaje. Con el objetivo de completar los datos obtenidos mediante el análisis de las fotografías aéreas y hacer más evidentes los cambios producidos en el paisaje costero se realizó una búsqueda de 
distintas fotografías antiguas que se compararon con fotografías actuales realizadas desde los mismos puntos de vista.

\subsubsection{Procedimientos}

\section{A) Ortorectificación}

Debido a un conjunto de factores entre los que destacan la curvatura de la tierra, el relieve pronunciado, las lentes fotográficas utilizadas, etc., las imágenes representadas en las fotografías aéreas presentan una serie de deformaciones que aumentan progresivamente al desplazarnos desde el centro de la imagen hacia los lados. Dichas deformaciones dificultan la medida de las superficies ocupadas por los elementos areales y por tanto la comparación con las dimensiones que dichos elementos presentan en la actualidad. También hacen difícil la comparación por sobreposición con los ortofotomapas que se editan actualmente al no encajar exactamente los mismos sectores geográficos representados en dichos soportes. Por todo ello es necesario proceder a la ortorectificación de las fotografías aéreas convencionales. Dicha corrección se ha realizado mediante la utilización del módulo Orthobase del software ERDAS.

\section{B) Tratamiento de datos en un Sistema de Información Geográfica (SIG)}

Dada la capacidad de realizar análisis espacial, el SIG se ha utilizado para el cálculo de distancias entre las distintas líneas costeras y para el cálculo de superficies de playa. Datos clave para la posterior avaluación y análisis de la evolución de la playa en la zona de estudio.

Con la incorporación de las distintas fotografías aéreas corregidas y georeferenciadas en el mismo sistema de coordenadas (UTM) en un SIG (Arcview 3.2) se realizó la fotointerpretación de todas las imágenes digitalizando y extrayendo la línea de costa y la superficie de playa de cada una de ellas. Posteriormente, se calcularon la superficie de playa y las distancias relativas ente las líneas de costa de la serie de años analizados. Con todos estos datos se pudo determinar la tasa de evolución de la línea de costa.

\section{C) Estadística: Cálculo de la tasa de evolución}

La tasa de evolución de la zona costera indica el desplazamiento que puede experimentar una playa en un año. Existen distintos métodos para su estimación, entre ellos el incremento neto (EPR = End Point Rate), usado en el presente estudio, y útil cuando lo que se pretende es evaluar en términos estrictos el retroceso o avance de un sector costero (Jiménez, 1998).

Dicho método utiliza únicamente dos posiciones de la línea costera, generalmente la más antigua y la más actual de todas las disponibles, despreciando las posiciones intermedias. A partir de esas dos líneas se calcula el desplazamiento experimentado entre esas dos posiciones y se divide por los años transcurridos entre ambas. Para ello se dibuja una línea paralela a la línea de costa, en la cual se definen un conjunto de puntos a partir de los cuales se calcula la distancia a cada una de las dos líneas de costa que se toman como base de la comparación: la de 1956 y la de 2003. Las distancias obtenidas se dividieron por los 47 años transcurridos entre los dos eventos. 


\subsection{Resultados}

Los procesos de acreción son propios de las costas bajas y responsables del desarrollo y crecimiento de las playas y otras morfologías costeras de acumulación. Sin embargo, en las últimas décadas, determinadas actuaciones humanas, han modificado la dinámica costera a través de la regulación de los cursos fluviales, la alteración de la dirección de las corrientes de deriva litoral con la construcción de distintas infraestructuras (puertos, espigones,...). Todo ello ha provocado un cambio de la tendencia evolutiva natural en la mayoría de sectores de costa de acumulación, convirtiéndolos en zonas donde se imponen los procesos erosivos.

A pesar de todo ello, la playa de Sa Riera es una de las pocas playas del litoral catalán que no presenta problemas de erosión sino todo lo contrario ya que manifiesta un balance sedimentario positivo, de manera que en las últimas décadas ha aumentado su anchura y en consecuencia se ha producido un avance de la línea de costa.

\subsubsection{Evolución de la playa de Sa Riera en el período 1956-2003}

La costa evoluciona como resultado de la acción integrada de diferentes agentes dinámicos que actúan a distintas escalas temporales y espaciales. Dicha diferencia de escala se refleja en una respuesta morfológica diferenciada (Sánchez-Arcilla y Jiménez, 1994). Por ello, en los estudios sobre evolución costera es imprescindible determinar a priori cual será la escala de estudio. En este caso la escala de análisis escogida ha sido una escala media, ya que los cambios analizados abarcan un período temporal de varias décadas. Dichos cambios se explican, principalmente, por las variaciones en el transporte longitudinal de sedimentos bajo el control del oleaje dominante a lo largo del año.

Como resultado de la realización de todos los procedimientos detallados en el apartado de la metodología se ha obtenido una medida de la playa seca representada en planta (ver la figura 2) donde se constata un aumento importante del volumen de arenas depositadas y por lo tanto un aumento de la superficie de playa y un avance de la línea costera.

En el año 1956 se puede apreciar como un pequeño conjunto de rocas llamadas Sa Pirolta separaban la pequeña bahía en dos sectores: el de Sa Riera propiamente dicho y la acumulación de arena situada más al oeste que era denominada la playa del Rei. Una configuración paisajísticamente más diversa que la actual.

Pocos años después, en la década de los 60, ambas playas continuaban estando separadas mientras que se detectan nuevas acumulaciones de arena en las proximidades del sector rocoso de separación.

En la imagen correspondiente a 1977 se puede apreciar como los dos sectores de playa ya se han unido debido a que las nuevas deposiciones de arenas cubrieron las rocas de $\mathrm{Sa}$ Pirolta que hasta el momento las separaban. Asimismo la superficie total de la playa emergida aumenta gradualmente, tendencia que corroboran las imágenes posteriores correspondientes a los años 1991, 1998 y 2003.

En la figura 3 se han superpuesto las superficies de playa obtenidas para el conjunto de años analizados. De dicha superposición se puede establecer que no ha habido cambios en la tendencia progradante de la playa de Sa Riera a lo largo de los casi 50 años analizados, en los cuales siempre, con menor o mayor intensidad, se ha visto bajo el predominio de los procesos de acumulación.

El aumento total de la superficie de la playa seca ha sido estimado en 0,75 hectáreas $\left(7500 \mathrm{~m}^{2}\right.$ ). Así mientras que en 1956 las dos playas existentes entonces (Sa Riera y playa del Rei) ocupaban en total una superficie de 1 hectárea aproximadamente, en la actualidad 

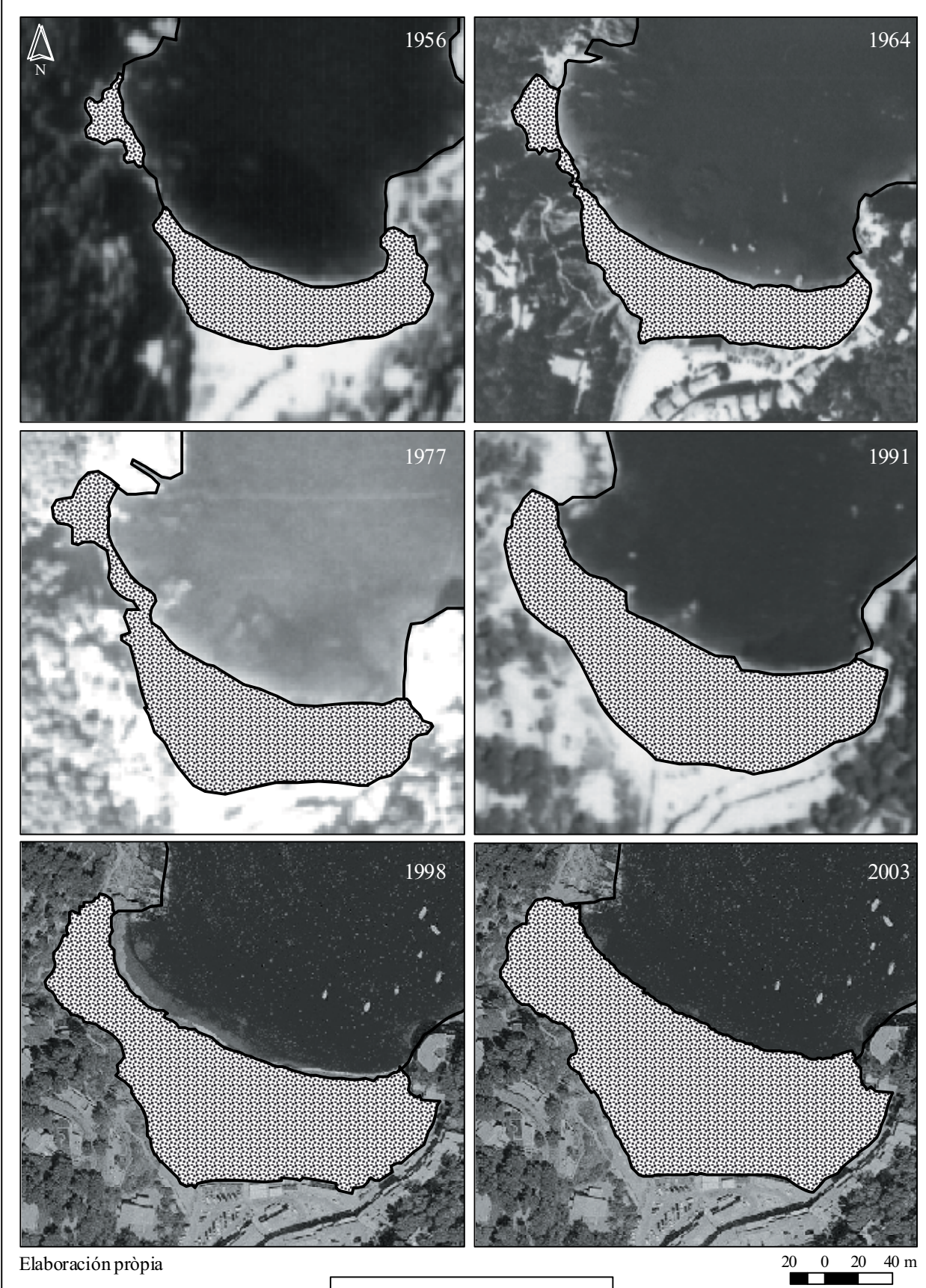

Elaboración pròpia

$$
\text { Superficie de playa }
$$

FIgURA 2. Evolución de la superficie de playa de Sa Riera (1956-2003). 


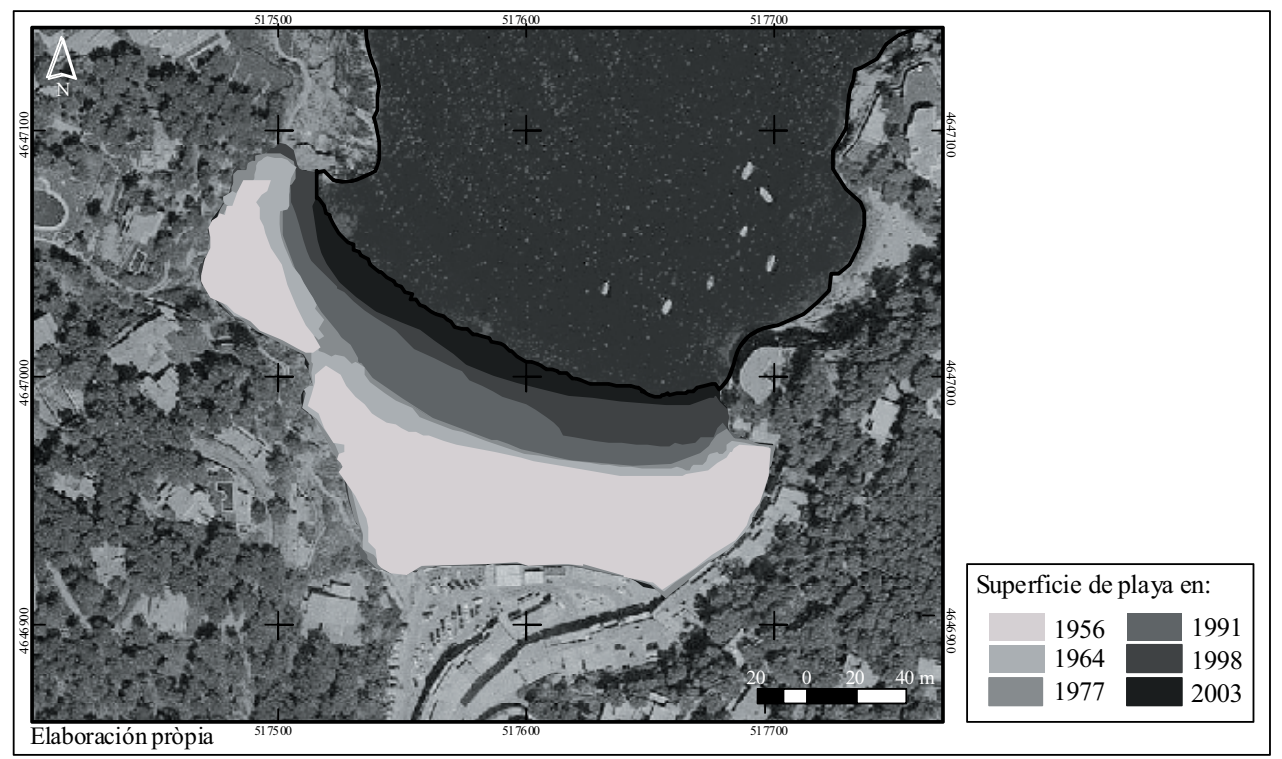

FIGURA 3. Superposición de las distintas superficies de playa (1956-2003).

la extensión de la playa emergida es de 1,73 hectáreas. Dicho aumento ha tenido lugar a diferentes ritmos a lo largo del período analizado ya que si bien en los primeros 30 años (desde 1956 a 1977) el incremento fue de 0,16 hectáreas, desde 1977 hasta el año 2003 la acreción avanzó con un ritmo mayor y el aumento de superficie fue de 0,59 hectáreas.

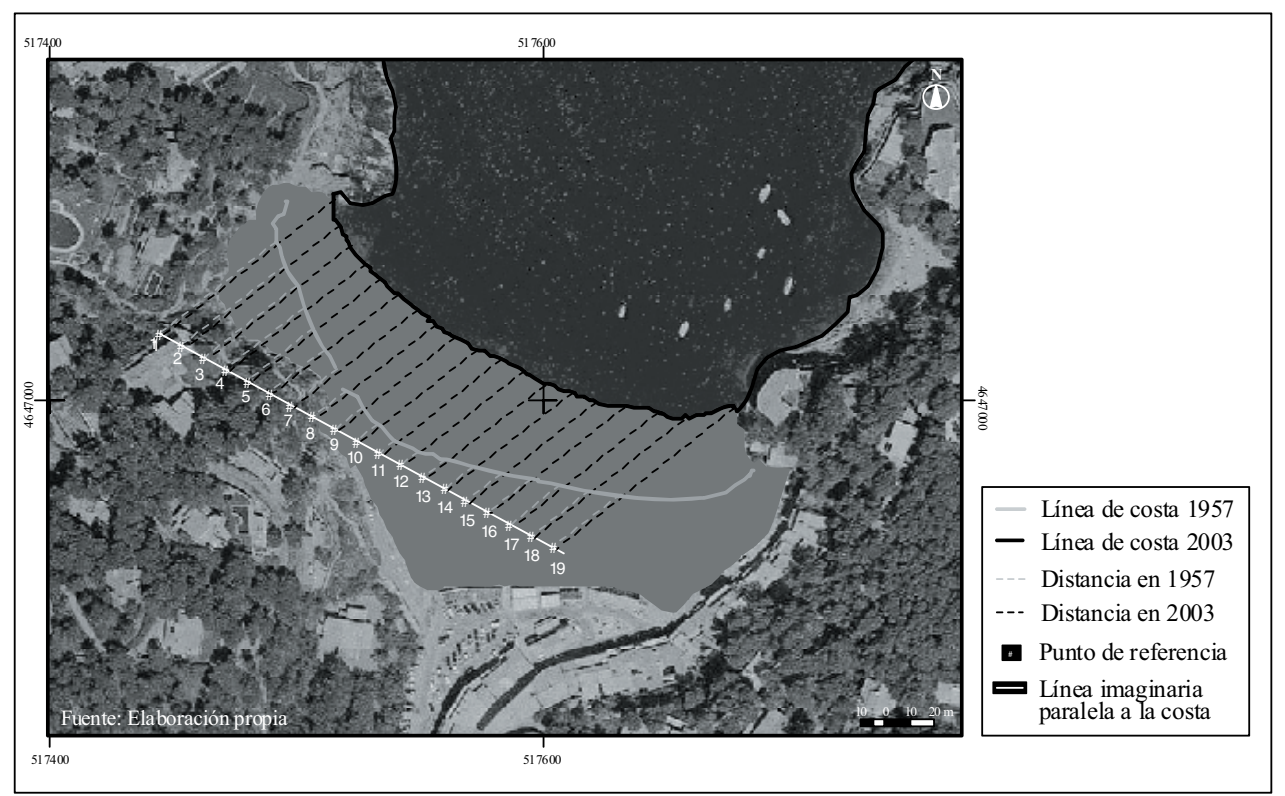

Figura 4. Puntos de control utilizados para el cálculo de la tasa de evolución. 


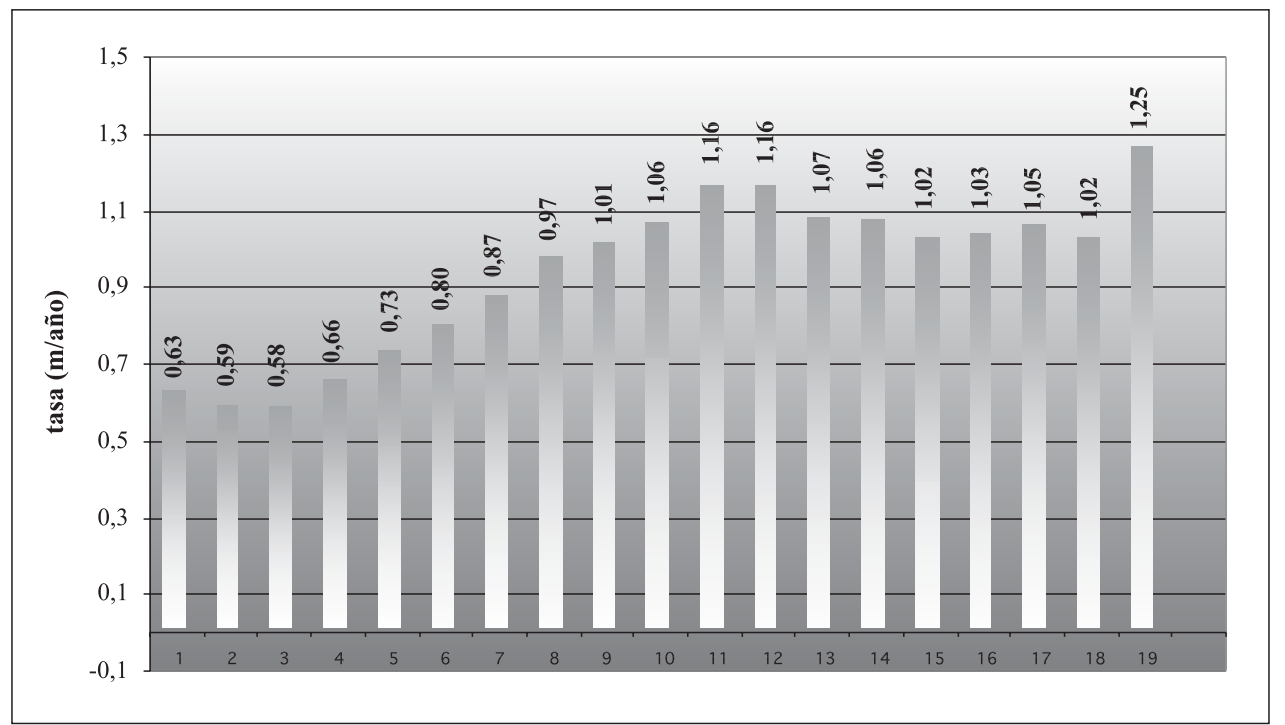

Figura 5. Tasas de evolución de la playa de Sa Riera en cada uno de los puntos de control establecidos.

A partir de las líneas de costa del primer y último año estudiado se ha calculado la tasa de evolución de la acreción de la cala de Sa Riera (ver figura 4).

Se observa como en todos los puntos de control utilizados los valores son positivos, lo que indica que la acumulación de arena se produce a lo largo de toda la playa. A pesar de ello, se distinguen dos ritmos de crecimiento diferenciados: el de la cala de Sa Riera propiamente dicha y el de la antigua cala del Rei, al oeste de la anterior. Las tasas de crecimiento más bajas, que no alcanzan el metro por año, se dan en el sector situado más al oeste, mientras que la acreción va en aumento a medida que los puntos de control se encuentran situados hacia el este, alcanzando valores superiores al metro por año. Este comportamiento diferenciado es debido a la orientación de la bahía, (SW-NE) que provoca que su sector oeste quede más protegido, lo que dificulta levemente la acumulación de los sedimentos arenosos. En cambio el centro y el este de la cala quedan totalmente expuestos por lo que el material trasportado en dirección norte-sur a sur se deposita en ese sector, a pesar de que posteriormente el oleaje pueda redistribuirlo.

A partir de los resultados obtenidos puede considerarse que la cala de Sa Riera se encuentra actualmente en una fase claramente progradante. Uno de los fenómenos típicos que ocurren en las playas progradantes, con una importante acumulación de material sedimentario, es la colmatación de algunos sectores. Normalmente ocurre que se anulan pequeños salientes costeros debido a la formación de tómbolos y al relleno progresivo de las bahías. Este es el caso de Sa Pirolta, un conjunto de rocas, que como se veía en fotografías aéreas de años anteriores, separaban las dos playas. En la figura 6 se puede observar por comparación entre una fotografía antigua y otra de actual la magnitud del proceso de acumulación que ha tenido lugar en estos años.

A pesar de que por regla general las pequeñas playas abrigadas que se encuentran en los tramos de costa rocosa constituyen en sí mismas células litorales, en cuanto se considera que no hay entradas ni salidas de sedimentos procedentes de otras células contiguas, no ocurre así en Sa Riera a pesar de que se halla enclavada en el sector litoral del cabo de Begur. 

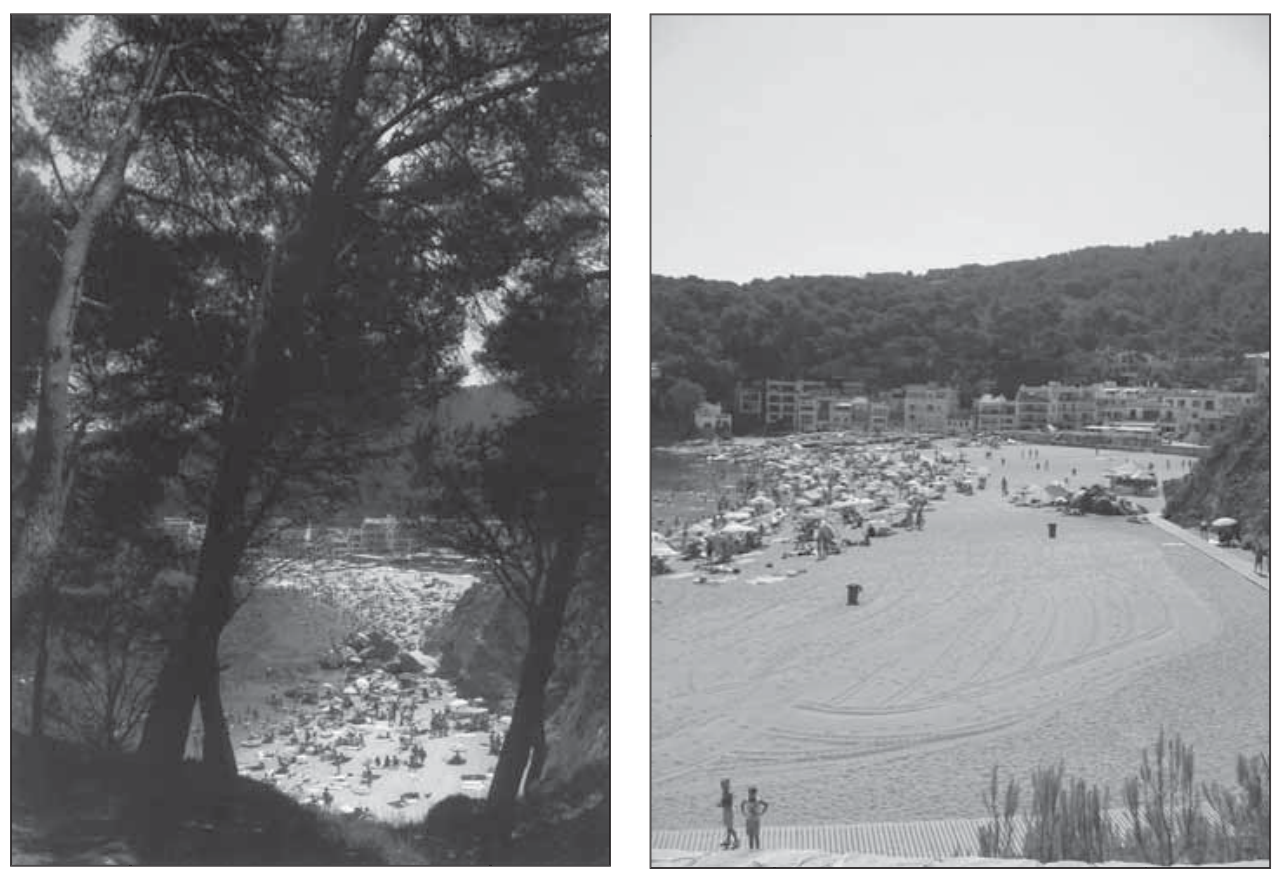

Figura 6. Imágenes de la cala de Sa Riera en los años 60 (izquierda) y en 2003 (derecha) donde se observa la acreción de la playa en este período.

En este caso la dinámica litoral nos indica la existencia de un transporte longitudinal que alimenta la acreción de la playa. En consecuencia el material acumulado en Sa Riera tiene su origen en la deriva litoral que tiene lugar en la larga playa expuesta de Pals, situada más al norte. Este sector costero posee un shelf poco profundo y una buena alimentación de sedimentos procedentes de los ríos Ter y Daró. Debido a que el promontorio rocoso que separa las playas de Pals y de Sa Riera no es muy pronunciado, no puede actuar de barrera total al transporte longitudinal que sigue un sentido norte-sur, el predominante en esta costa. Menos aún cuando con el paso del tiempo los pequeños entrantes existentes en el promontorio se han visto también colmatados por las arenas provocando que en la actualidad la corriente de deriva lo sobrepase y deposite su carga en la playa de Sa Riera, que se ha convertido de hecho en el apéndice meridional de la primitiva célula litoral del sector costero del bajo Ter.

\subsubsection{Consecuencias socioambientales de los cambios en la playa}

Los cambios costeros se califican como problemáticos cuando comportan un conjunto de implicaciones negativas sobre los recursos y usos propios del espacio litoral, de modo que pueden afectar a los intereses socioeconómicos y a los valores naturales (Jiménez, 2001).

Si bien parece comprensible que las playas que padecen procesos de erosión sean percibidas como problemáticas no lo parece tanto que también ésta sea la imagen de las playas dominadas por la acreción. 
El caso de la playa de Sa Riera, una costa claramente progradante como ha quedado establecido en los apartados anteriores, pone de relieve que al menos un determinado perfil de usuario percibe como negativos los cambios que han tenido lugar en las últimas décadas. En principio parecería que el fenómeno de acreción sería bien recibido socialmente dado que un aumento de la superficie de playa podría significar un aumento de su capacidad de carga. Sin embargo las actividades relacionadas con el sector náutico se han visto afectadas con la progradación de la línea de costa, ya que la zona de amarre de las embarcaciones se traslada cada vez más hacia mar adentro y a una mayor profundidad, además de hacerse más engorroso el mover las embarcaciones por la playa cuando deben ser varadas, motivos por los cuales este sector de usuarios ha manifestado su malestar.

Ha habido también quejas para parte de aquellos usuarios de playa que han manifestado su nostalgia por la configuración primitiva de la bahía y que consideran que la playa actual ha perdido calidad paisajística.

Finalmente otro de los problemas socioambientales que han aparecido hace referencia al torrente que desemboca en la playa. Debido a su pequeño caudal y al aumento de la anchura de la playa emergida no tiene suficiente fuerza como para que el agua de lluvia llegue hasta la línea de orilla con lo que el agua queda estancada en la arena ocasionando problemas de salubridad y de degradación de la calidad visual del paisaje.

\section{Conclusiones}

La acreción de las playas es el resultado de los procesos morfodinámicos vigentes hasta hace pocas décadas en todas las costas bajas. En la actualidad y debido a un conjunto de intervenciones humanas en las zonas costeras la progradación de la línea de costa se ha visto substituida por el predominio de los procesos erosivos que conducen al retroceso de la línea de costa. Las playas progradantes como la cala de Sa Riera se convierte en casos singulares bajo los condicionantes actuales.

La cala de Sa Riera no se comporta como una célula litoral independiente sino que a efectos del transporte longitudinal de sedimentos forma parte de una célula más extensa que incluye el sector sur del litoral del bajo Ter. Las corrientes de deriva litoral siguen un sentido norte-sur y alimentan la cala de Sa Riera con sedimentos procedentes de la playa de Pals.

La no existencia de obstáculo alguno que interfiera con el transporte longitudinal de material, ha permitido que la acreción haya avanzado de forma ininterrumpida. Se ha cuantificado, mediante la digitalización de la superficie de la playa emergida en las fotografías aéreas del período 1956-2003, en 1,25 m/año la tasa máxima de avance de la línea de costa. Por lo tanto, observada su evolución pasada en un rango temporal de 50 años, se puede prever que el proceso de progradación continuará afectando dicha playa a no ser que se alivie la acumulación utilizando las arenas «sobrantes» para aprovecharlas en la regeneración de otras playas que sufren el mal contrario: la regresión costera, evitando así extracciones procedentes de los lechos fluviales o de los bancos de arena sumergidos, y evitando los enormes efectos negativos que dichas extracciones comportan para el medio ambiente.

Se ha constatado también la disconformidad de algunos perfiles de usuario con la acreción de la playa debido a algunos inconvenientes para las actividades nautico-recreativas.

\section{Bibliografía}

BRUNN, P., (1962): Sea-level rise as a cause of shore erosion. J. Waterways ans Harbors Division, $88,117-130$ 
BORES, P.S. (1990): Formas costeras. Escuela Técnica Superior de Ingenieros de Caminos, Canales y Puertos. Madrid.

BOU, J. (1994): Uso de la fotogrametría en los estudios de morfología costera. Aplicación al Delta del Ebro. Tesina de especialidad, ETS, Enginyers de Camins Canals i Ports, Universitat Politècnica de Catalunya.

CARTER, R.W.G. (1988): Coastal environments. An introduction to the Physical, Ecological and Cultural Systems of Coastline. London. Academic Press.

COMAS, D. Y RUIZ, E. (1993): Fundamentos de los sistemas de información geográfica. Barcelona. Editorial Ariel.

JIMÉNEZ, J.A. (1996): Evolución costera en el delta del Ebro. Un proceso a diferentes escalas de tiempo y espacio. Tesis doctoral. Universitat Politècnica de Catalunya. Barcelona.

KOMAR, P.D. (1998): Beach processes and sedimentation. 2ona Ed., Prentice Hall.

MORALES, J. \& TEJADA, M. (1997): Nuevas tecnologías y dinámica costera: Teledetección y SIG, Geología costera. Algunos aspectos metodológicos y ejemplos locales, pp.173-199. Universidad de Huelva. Huelva.

NONN, H. (1974): Géographie des littoraux. PUF. París.

OJEDA ZÚJAR, J. (2001): Métodos para el cálculo de la erosión costera. Revisión, Tendencias y Propuestas. Boletín del AGE, Vol. 30, pp. 103-118.

ORTIZ, M.A. (1997): Anàlisi de diferents metodologies per a la captura de la línia de costa. Estudi de precisions $i$ costos. Tesina d'especialitat. Escola Tècnica Superior d'Enginyers de Camins, Canals i Ports de Barcelona (UPC). Barcelona.

PASKOFF, R. (1987): Côtes en danger. Masson. París.

PASKOFF, R. (1994): Les littoraux. Ed. Masson. París.

SÁNCHEZ-ARCILLA A y JIMÉNEZ, J.A. (1994): Ingeniería de playas (I): Conceptos de morfología costera. Revista de Ingeniería del Agua, Vol. 1, pp. 97-114.

SÁNCHEZ-ARCILLA, A. y JIMÉNEZ, J.A. (1995): Evolución en planta/perfil de una playa. Métodos predictivos. Revista de Ingeniería del Agua. Vol. 2, pp. 119-132. 